\title{
HYBRID ACTIVE VIBRATION CONTROL IN WIND TURBINE TOWERS
}

\author{
NÍCOLAS R. KARNOPP ${ }^{1}$, HERBERT M. GOMES ${ }^{2^{*}}$ \\ ${ }^{1,2}$ Federal University of Rio Grande do Sul, Mechanical Engineering Department, \\ Av. Sarmento Leite, 425, sala 202, $2^{\circ}$. andar, 90050-170, Porto Alegre, RS Brazil. \\ ${ }^{1}$ nicolas.rk@hotmail.com ${ }^{2}$ herbert@mecanica.ufrgs.br.
}

Keywords: Active Vibration Control, LQR, Wind Turbine Towers, Tuned Mass Dampers.

\begin{abstract}
Due to the demand for renewable and clean energy sources, the generation of electricity from wind farms has become a reality in Brazil. The central unit of energy generation in these farms are the wind turbines composed of tower, nacelle, and blades. Reduction in mass and material is always desirable in these units due to the final cost impact on a wind farm consisting of several units. The main external excitation source in these systems is the wind, or the system itself, as in the case of possible imbalance. The design of the support tower and foundations must take into account quasi-static stresses as well as the varying and transient stresses the system may be exposed in the service life, which could lead to fracture or fatigue problems. Minimizing the mass of these structures and keeping their vibration levels at acceptable values is a difficult task that can be achieved by controlling vibration either passively (with Dynamic Vibration Absorbers, DVA) or actively with actuators. This paper proposes to investigate the active vibration control for wind turbine systems with hybrid active vibration control.
\end{abstract}

\section{INTRODUCTION}

Nowadays Brazil is the 8th country in the world in terms of wind energy production. The Brazilian energy mesh currently counts for approximately $8.3 \%$ of the total energy produced, losing to $60.9 \%$ from the hydroelectric matrix and $9.3 \%$ from biomass plant. The Brazilian Association of Wind Energy estimates that Brazil has a wind potential greater than $500 \mathrm{GW}$ and an installed capacity is $12 \mathrm{GW}^{[1]}$. More than half of the energy consumed by the country's northeast region is already from wind farms.

New wind turbines flexibles make generator towers more vulnerable to external actions extreme wind, wave effects (offshore), and seismic excitations. Absorption systems energy in structures has been used extensively in civilian structures as a cheap way and relatively efficient of limiting vibrations in these structures, however of limiting efficiency and low robustness. The possibility of having an active control system that allows the change of the dynamic property of the structure, in real-time, to deal with this variable loads and most of the time random, opens new horizons for bolder and efficient structures.

The use of wind turbines has become a reality, mainly in propitious regions to this objective like the northeast and coast of Brazil depending on the intensity of the winds and their constancy. The use of passive dynamic vibration absorbers has limited efficiency and 
compromised when the active excitation is different from those for which they went projected. Furthermore, in the case of active control, the need for the electricity to use actuators is not a problem as the tower itself is being generated. This attenuation of vibration aims, ultimately, to increase the life spam of tower structure in terms of fatigue, to allow slender and higher structures. Therefore, the wind turbine can be subjected to more intense winds (for the best use of wind potential). At the same time, the attained vibration attenuation allows the correct operation of moving mechanical parts (amplifier boxes) and sensitive components present in the nacelle of the wind turbine.

This work aims to study the behavior of wind turbine towers vibration's behavior due to loads originated by strong winds and compare systems used to mitigate such vibrations. So, the main objective is to evaluate, using a passive DVA, and a hybrid system (active + passive), the acceleration attenuation caused at nacelle, and the loads caused to the wind turbine structure under conditions of wind excitation.

\section{LITERATURE REVIEW}

There are many types of vibration dampers, of which few become very popular due to his capacity to mitigate structural vibrations. Are they: Tuned-Mass Damper, Tuned-Liquid Dampers, and Controllable Fluids Damper ${ }^{[2]}$. The tuned-mass damper (DVA) has introduced by Denhartog ${ }^{[3]}$ and is the simple system mass-spring-damper coupled to the main structure, becoming an additional degree of freedom that will serve to dissipate the vibration energy

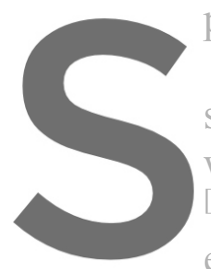
present in the primar

The tuned-liquid slender structures by

wind turbine towers,

find out the mass

efficiency of the dampin
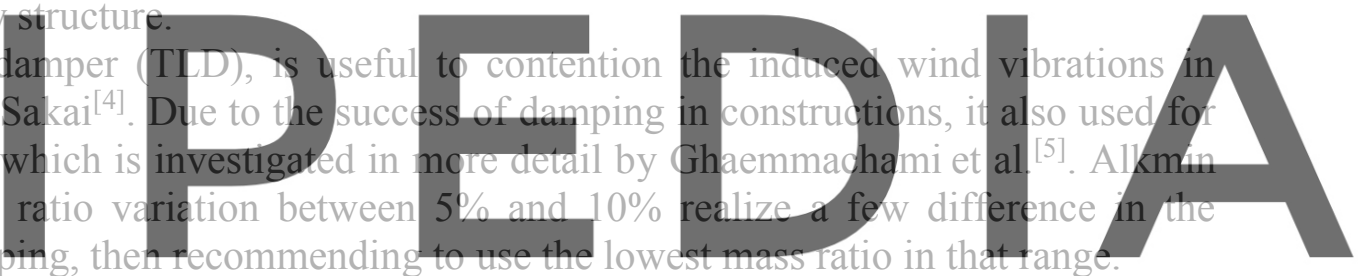

Controllable Fluids Dampers use controllable fluids within the damper, with emphasis on

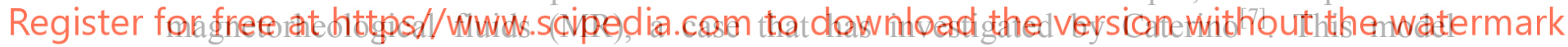
modifies how mechanical properties of the fluid in real-time through the action of magnetic fields, according to an instantaneous response from the tower. He also verified that with a Controllable Fluids Damper positioned at the base tower that, in some cases, the bending moment in the base decreases at the expense of a greater displacement at the top of the tower. However, even though these dampers, in their passive form, are very effective for harmonic loads at frequencies very close to the frequency for which they were tuned, their application is quite limited, since there is no dominant frequency in the vibration of wind turbines and they can inclusive aggravate the vibration of the tower at depending on the frequency ${ }^{[8,9]}$.

In situations where quick control action is required, a passive DVA may not have a satisfactory answer. For such cases there active ad hybrid dampers, where increase a hydraulic actuator in parallel with DVA stiffness and damping. Lima et al. ${ }^{[10]}$ perform a study that compares these three types of dampers under harmonic excitations and observed that the hybrid DVA is the one that presents the faster answer and biggest decrease in tower oscillations. 


\section{THEORETICAL BASIS}

\subsection{Essential parts of a wind turbine}

Wind turbines are equipment that aims to extract the energy from wind, converting in electric energy. They do it by their wings, which can capture this energy either because of the lift effect on wings when these are formed by aerodynamic profiles. The wings start moving, spinning around the turbine axis connected to an amplifier box that has the function to deliver torque and rotation to a generator that, in its turn, converts mechanical energy into electrical energy.

In the case of wind turbines of horizontal axis, the most used in large-scale generation, there is also the nacelle. The nacelle is a compartment that contains the most of elements mentioned above, located at the top of the tower, at heights of up to 160 meters. It is also the heavier component of the system and for this reason makes it necessary to control possible vibrations generated by the wind turbine operation. Damping is often obtained by Dynamic Vibration Absorbers (DVA) in order to regulate and attenuate these vibrations. A schematic draw of the essential parts of a wind turbine and a representation of DVA installed in a wind turbine are shown in Figures 1(a) and 1(b), respectively. In this work, the acronyms DVA (Dynamic Vibrations Absorber) and TMD (Tuned Mass Damper) will be used as synonyms.
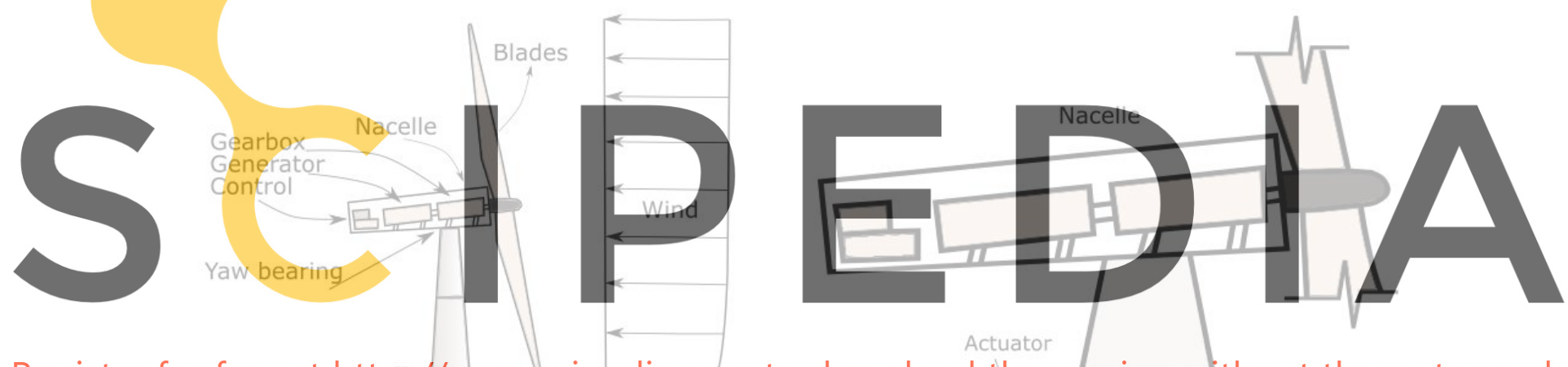

Register for free at https//www.scipedia.com to download the version without the watermark
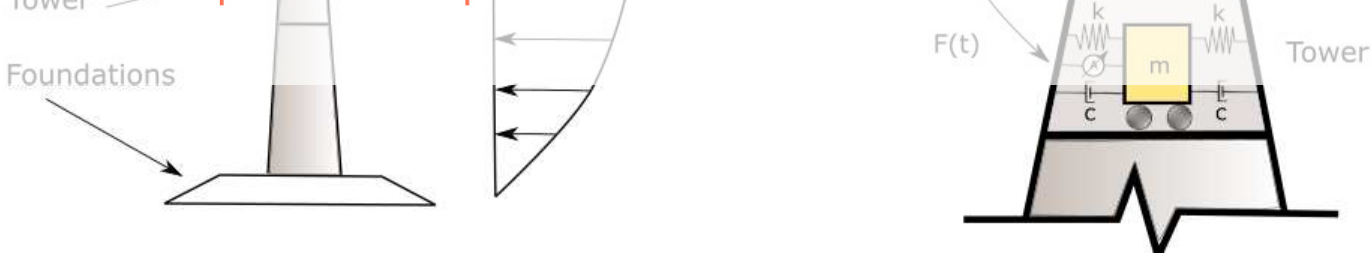

Figure 1: (a) Main parts of a wind turbine. (b) Dynamic Vibration Absorber (DVA) located near the Nacelle.

\subsection{Equations of motion}

Applying Newton's second law (Eq. 1) to each of the existing masses in the free body diagram the equations of motion are obtained and can be represented in a matrix form starting from the equations of motion ${ }^{[11]}$ (Eq. 1).

$$
m_{i} \overrightarrow{\ddot{x}}_{i}=\sum_{j} F_{i j}
$$

where $\sum_{j} F_{i j}$ denotes the sum of all forces $j$ acting on mass $m_{i}$. 


$$
[M] \ddot{\vec{x}}(t)+[C] \dot{\vec{x}}(t)+[K] \vec{x}(t)=\vec{F}
$$

In the context of a Finite Element Analysis (FEA), $[M],[C]$, and $[K]$ are the mass, damping, and stiffness matrices, respectively, for all degrees of freedom(DOF). The vectors $\vec{x}, \dot{\vec{x}}, \ddot{\vec{x}}$ and $\vec{F}$ are the displacement, velocity, acceleration, respectively. This system of second-order differential equations can be solved in the time or frequency domain. . Eq. 2 is valid for each DOF. In the time domain, Newmark's integration scheme is here used to obtain the time histories for each DOF. For the entire structure to be represented by a system of equations, one should rotate local mass, damping and stiffness matrices to the global coordinate system, according to the procedure like in case of stiffness matrix $\left[\boldsymbol{k}_{e}\right]=[\boldsymbol{R}]^{T}\left[\boldsymbol{k}_{\boldsymbol{e}}^{\boldsymbol{L}}\right][\boldsymbol{R}]$, where matrix $[\boldsymbol{R}]$ is the rotation matrix from local to global coordinate system, $\left[\boldsymbol{k}_{\boldsymbol{e}}^{\boldsymbol{L}}\right]$ is the local stiffness matrix for element $e$ and $\left[\boldsymbol{k}_{e}\right]$ is the same matrix in the global coordinate system. The local matrices have dimensions of dof $\times$ edof, where edof is the number of DOF of a single finite element. After matrices rotation, they are superimposed in a global matrix $[K]$ according to the global numbering and shared DOF from the neighbor's elements. The global matrix dimensions will be $n \times n$, where $n$ is the total number of DOF of the system. The vectors will have $n \times 1$.

\subsection{Newmark's algorithm for time integration}

The solution of the time-domain equation follows the implicit numerical integration method of Newmark, which consists of three equations of recurrence, considering the linear variations

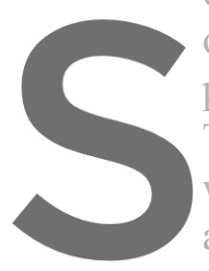
of displacement, veldci parameters $\alpha$ and $\beta$, th Thus, time is discretize was $\Delta t=1 \times 10^{-3} \mathrm{~s}$ acceleration, and veloci
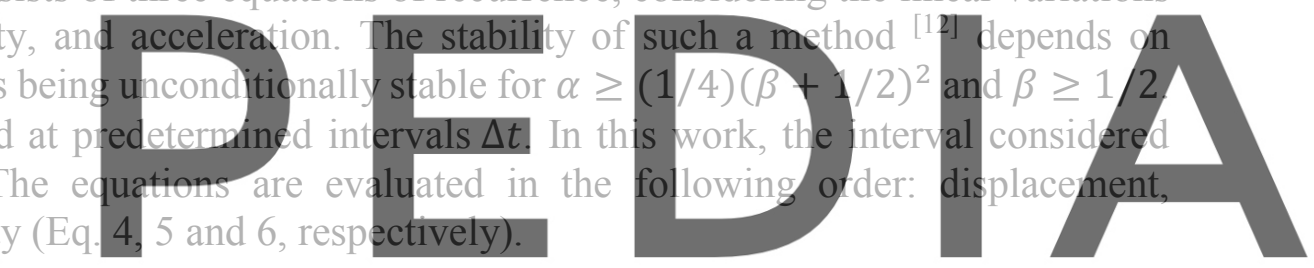

Register for free at https//www.

$$
\begin{gathered}
\times\left\{\overrightarrow{\mathrm{F}}_{i+1}+\left[\mathrm{M}_{i}\right]\left(\frac{1}{\alpha(\Delta t)^{2}} \vec{x}_{i}+\frac{1}{\alpha \Delta t} \dot{\vec{x}}_{i}+\left(\frac{1}{2 \alpha}-1\right) \ddot{\vec{x}}_{i}\right)\right. \\
\left.+[\mathrm{C}]\left(\frac{\beta}{\alpha \Delta t} \vec{x}_{i}+\left(\frac{\beta}{\alpha}-1\right) \dot{\vec{x}}_{i}+\left(\frac{\beta}{\alpha}-2\right) \frac{\Delta t}{2} \ddot{\vec{x}}_{i}\right)\right\} \\
\ddot{\vec{x}}_{i+1}=\left[\frac{1}{\alpha(\Delta t)^{2}}\right]\left(\vec{x}_{i+1}-\vec{x}_{i}\right)-\left[\frac{1}{\alpha(\Delta t)^{2}}\right] \dot{\vec{x}}_{i}-\left(\frac{1}{2 \alpha}-1\right) \ddot{\vec{x}}_{i} \\
\left.\dot{\vec{x}}_{i+1}=\dot{\vec{x}}_{i}+\left[(1-\beta) \ddot{\vec{x}}_{i}+\beta\right) \ddot{\vec{x}}_{i+1}\right] \Delta t
\end{gathered}
$$

\subsection{Designing of a DVA}

For the appropriate project of a DVA, the methodology described in ${ }^{[3]}$ is followed. For a 2 degree of freedom (represented in Figure 2), the equations of motion are described by the system of equations in Eq. 6 .

$$
\left\{\begin{array}{c}
m_{H} \ddot{u}_{H}+c_{H} \dot{u}_{H}+c_{T}\left(\dot{u}_{H}-\dot{u}_{T}\right)+k_{H} u_{H}+k_{T}\left(u_{H}-u_{T}\right)=F(t) \\
m_{T} \ddot{u}_{T}+c_{T}\left(\dot{u}_{T}-\dot{u}_{H}\right)+k_{T}\left(u_{T}-u_{H}\right)=0
\end{array}\right.
$$




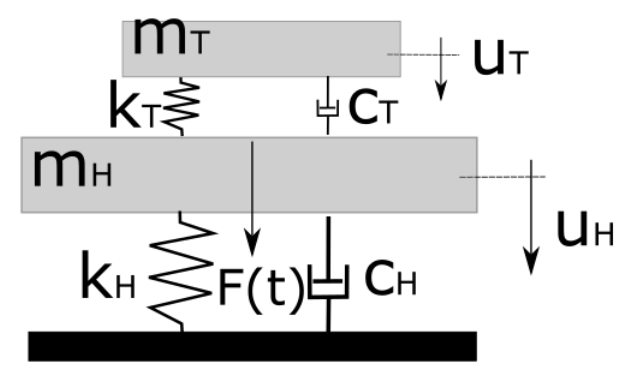

Figure 2: Two degrees of freedom system.

To facilitate the system's solution, Table 1 introduces some dimensionless parameters. For a harmonic excitation force $F(t)=\cos (\omega t)$, replacing this and the dimensionless parameters in Eq.(7), we arrive at the system of equations.

$$
\begin{aligned}
{\left[-\Omega^{2}+2 i \Omega\left(\zeta_{H}+\beta \gamma \zeta_{T}\right)+\left(1+\beta^{2} \gamma\right)\right] U_{H}+\left[-2 i \Omega \beta \gamma \zeta_{T}-\beta^{2} \gamma\right] U_{T} } & =U_{H 0} \\
{\left[-2 i \Omega \beta \gamma \zeta_{T}-\beta^{2} \gamma\right] U_{H}+\left[-\Omega^{2} \gamma+2 i \Omega \beta \gamma \zeta_{T}+\beta^{2} \gamma\right] U_{T} } & =0
\end{aligned}
$$

This system can be resolved to the $U_{T} / U_{H 0}$ dynamic amplification factor as function of dimensionless mentioned parameters, by:

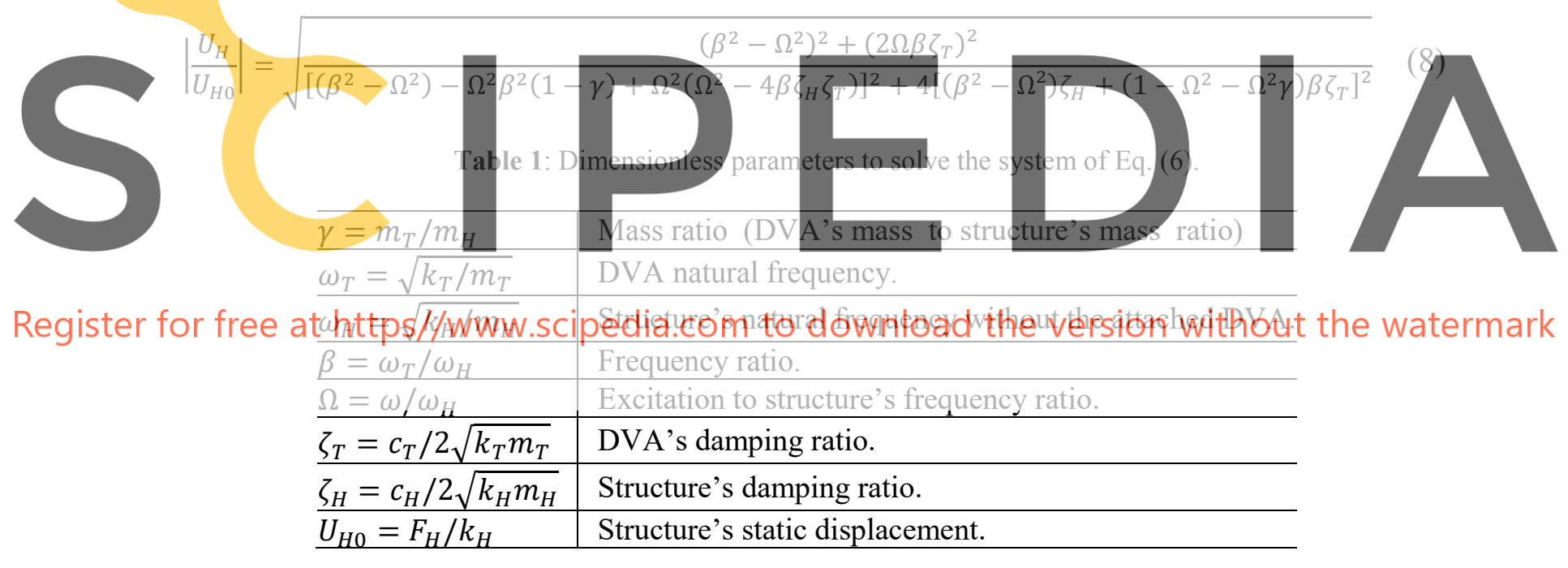

For a structure without damping $\left(\zeta_{H}=0\right)$, keeping the parameters $\beta, \gamma$ and $\zeta_{T}$ which are defined in the Figure 3, one can plot this expression in function of the excitation to structure's frequency ratio $(\Omega)$. Based on the observations made in the graph in Figure $3,{ }^{[3]}$ found the optimal parameters for a DVA applied to an undamped structure:

$$
\begin{gathered}
f_{T, o p t}=\frac{f_{H}}{1+m_{T} / m_{H}}=\frac{f_{H}}{1+\gamma} \quad \text { or } \quad \beta_{o p t}=\frac{1}{1+\gamma} \\
\zeta_{T, o p t}=\sqrt{\frac{3 m_{T} / m_{H}}{8\left(1+m_{T} / m_{H}\right)^{3}}}=\sqrt{\frac{3 \gamma}{8(1+\gamma)^{3}}}
\end{gathered}
$$

where the subscript opt refers to the optimized parameter and $f$ refers to the natural frequency. Such parameters can be applied to structures with low damping. 
In Figure 3, different values of $\zeta_{T}$ and the corresponding optimum values of the DVA to attenuate this amplification factor are plotted following Eq.(8).

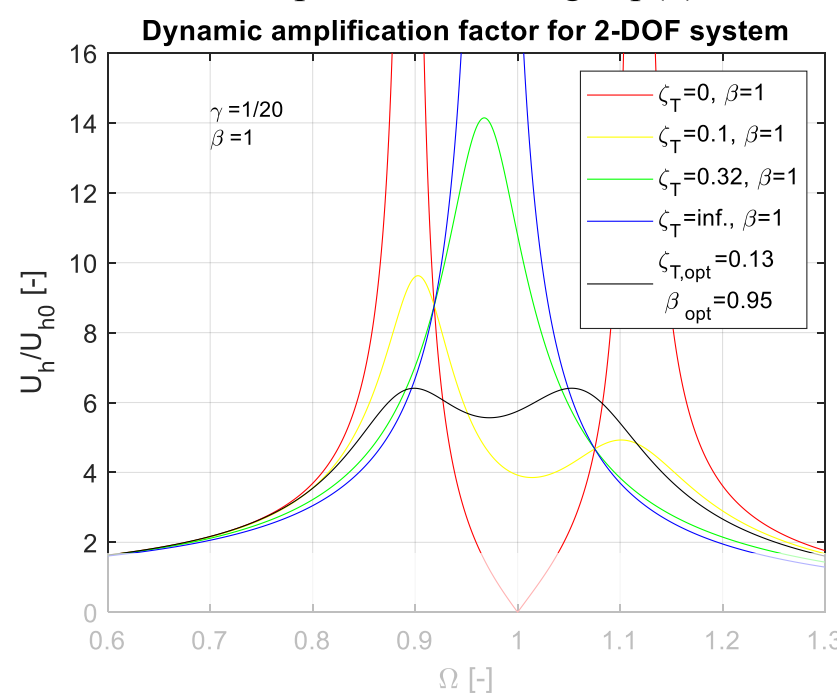

Figure 3: Dynamic amplification factor versus excitation to structure's frequency ratio ${ }^{[13]}$.

One can state some important observations about the DVA application: (i) The frequency DVA tuning should be quite accurate otherwise the attenuations will not be the optimum; (ii)

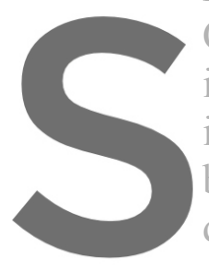
Compliance with the op is not advantageous; increases; (v) A good ch between efficiency and desired, as it will be suspended
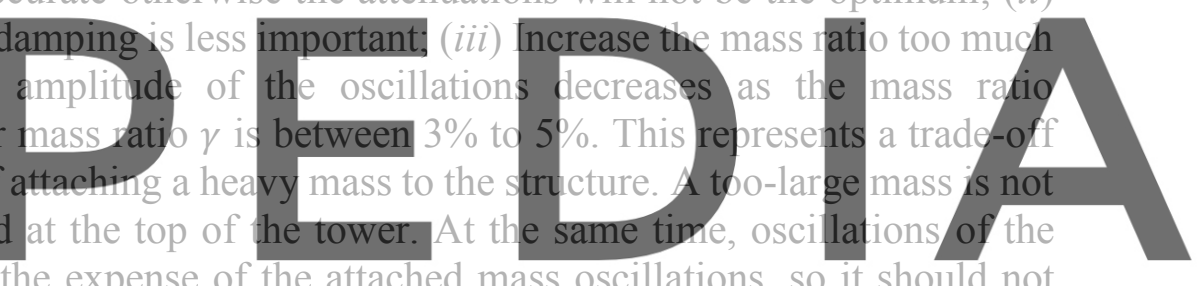

Register for free at https//WwW inscipedia.com to downiload the version without the watermark

\subsection{The design of a Linear Quadratic Regulator (LQR)}

For DVA to have active control, it is necessary to use a regulator, which takes place through actuators installed in parallel with the spring and damper present in the DVA. So, in the equations motions (Eq. 2), the term referring to force contains both a component referring to external forces and a component referring to forces controlling the actuator.

The Linear Quadratic Regulator (LQR) theory is used to design the control law used in the actuator, which is based on the theory of optimal control ${ }^{[14]}$. It aims in finding the control input $\overrightarrow{\boldsymbol{u}}(t)$ ) that minimizes the performance index. The $J$ index used is represented in the Eq. 11 assuming it also satisfies Eq. 12.

$$
\begin{aligned}
& J=\frac{1}{2} \int_{0}^{\infty}\left(\overrightarrow{\boldsymbol{x}}^{T}[\boldsymbol{Q}] \overrightarrow{\boldsymbol{x}}+\overrightarrow{\boldsymbol{u}}^{T}[\boldsymbol{R}] \overrightarrow{\boldsymbol{u}}\right) d t \\
& \dot{\overrightarrow{\boldsymbol{x}}}=[\boldsymbol{A}] \vec{x}+[\boldsymbol{B}] \overrightarrow{\boldsymbol{u}}, \text { for a given } \overrightarrow{\boldsymbol{x}}(0)
\end{aligned}
$$

where $\overrightarrow{\boldsymbol{x}}$ and $\overrightarrow{\boldsymbol{u}}$ are the state and control vectors, respectively. [Q] is a positive-defined or semidefined matrix of weights such that $\vec{x}^{T}[Q] \vec{x} \geq 0$, for $\vec{x} \neq 0$, and $[R]$ is a positive-defined matrix such that $\overrightarrow{\boldsymbol{u}}^{T}[\boldsymbol{R}] \overrightarrow{\boldsymbol{u}}>0$ for $\overrightarrow{\boldsymbol{u}} \neq \mathbf{0}$. 
To solve the minimization problem with a restriction, Eq. 12 and 13 are combined using the Lagrange multiplier $(\vec{\lambda})$, which brings us to Eq. 13, whose Hamiltonian is represented by Eq. 14.

$$
\begin{gathered}
J=\frac{1}{2} \int_{0}^{\infty}\left(\overrightarrow{\boldsymbol{x}}^{T}[\boldsymbol{Q}] \overrightarrow{\boldsymbol{x}}+\overrightarrow{\boldsymbol{u}}^{T}[\boldsymbol{R}] \overrightarrow{\boldsymbol{u}}\right) d t+\overrightarrow{\boldsymbol{\lambda}}^{T}([\boldsymbol{A}] \overrightarrow{\boldsymbol{x}}+[\boldsymbol{B}] \overrightarrow{\boldsymbol{u}}-\dot{\overrightarrow{\boldsymbol{x}}}) \\
H=(1 / 2)\left(\overrightarrow{\boldsymbol{x}}^{T}[\boldsymbol{Q}] \overrightarrow{\boldsymbol{x}}+\overrightarrow{\boldsymbol{u}}^{T}[\boldsymbol{R}] \overrightarrow{\boldsymbol{u}}\right)+\overrightarrow{\boldsymbol{\lambda}}^{T}([\boldsymbol{A}] \overrightarrow{\boldsymbol{x}}+[\boldsymbol{B}] \overrightarrow{\boldsymbol{u}}) .
\end{gathered}
$$

Using the variational principle and performing some algebraic manipulations, one arrives at the optimization conditions of $J$, that is represented in Eq. 15 and 16.

$$
\begin{gathered}
\dot{\vec{\lambda}}=-\frac{\partial H}{\partial \overrightarrow{\boldsymbol{x}}}=-[\boldsymbol{Q}] \overrightarrow{\boldsymbol{x}}-[\boldsymbol{A}]^{T} \vec{\lambda} \text { for } \vec{\lambda}(\infty)=0 \\
\frac{\partial H}{\partial \vec{u}}=[\boldsymbol{R}] \overrightarrow{\boldsymbol{u}}+[\boldsymbol{B}]^{T} \vec{\lambda}=0
\end{gathered}
$$

Thus, the optimal control input $\vec{u}$ is a function of $\vec{\lambda}$, so that:

$$
\vec{u}=-[R]^{-1}[B]^{T} \vec{\lambda}
$$

In this way, when solving to $\vec{\lambda}$ one has the solution for $\vec{u}$. However, as the boundary condition is given in the stationary state as $\vec{\lambda}(\infty)=0$ and the initial condition of $\vec{x}$ is given at the initial time $t=0$, this solution is not easily obtained. A popular method is to use the following relationships:
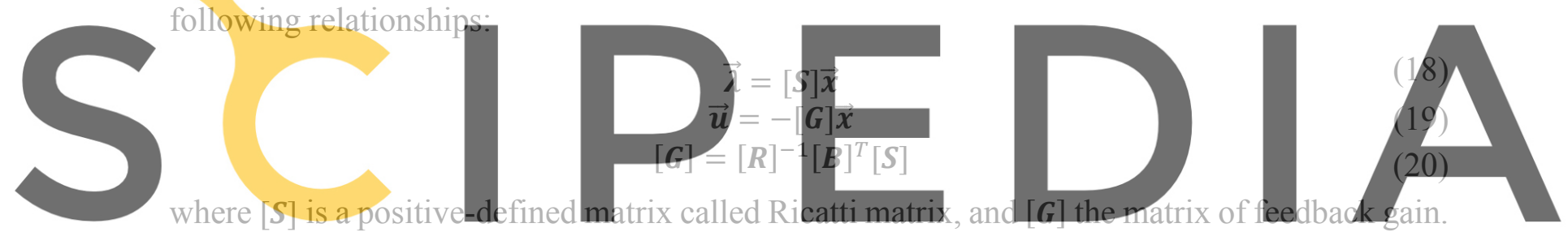

Replacing Eq.(18) in Eq. (17) and applying a slight algebraic manipulation we arrive at:

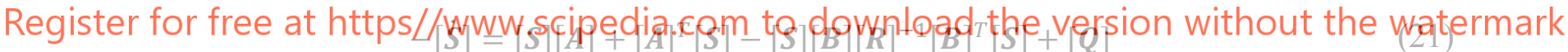

The above equation is a differential matrix equation and can solve using the stationary solution. When the system reaches the stationary regimem, the Ricatti matrix satisfies $[\dot{S}]=0$. Thus, we arrive at the Ricatti Algebraic Equation (RAE):

$$
\mathbf{0}=[\boldsymbol{S}][\boldsymbol{A}]+[\boldsymbol{A}]^{T}[\boldsymbol{S}]-[\boldsymbol{S}][\boldsymbol{B}][\boldsymbol{R}]^{-1}[\boldsymbol{B}]^{T}[\boldsymbol{S}]+[\boldsymbol{Q}]
$$

There some algorithms for solving RAE, one of the most popular being the Potter method. This method it will give the Ricatti matrix $[\boldsymbol{S}]$ and the feedback gain matrix $[\boldsymbol{G}]$, then can solve to $\vec{\lambda}$. With the gain matrix and other parameters, the system response is simulated over time. The only parameters that must be defined are the matrices $[\boldsymbol{Q}]$ and $[\boldsymbol{R}]$, and a trial and error procedure is used to perform little adjustments. For this work, a satisfactory result was achieved with the following matrices:

$$
\begin{gathered}
{[\boldsymbol{Q}]=10^{-2}[\boldsymbol{I}]_{2 n \times 2 n}} \\
{[\boldsymbol{R}]=0.5 \times 10^{-13}[\boldsymbol{I}]_{n f c \times n f c}}
\end{gathered}
$$

where $n$ is the number of degrees of freedom of the system and $n f c$ is the number of control forces. The matrix $[Q]$ has undergone an additional change, assigning the value $1.5 \times 10^{-1}$ to 
the elements $(n, n)$ and $(n-1, n-1)$ that are the DOF of the attached DVA in two directions. This was performed in order to constraint the vibration of the two degrees of freedom of the DVA, since there is a space constraint in the interior of the wind tower.

\section{METHODOLOGY}

The problem was represented by a code in MATLAB software, simulating a wind turbine tower that suffers the action of a spatial (3D) wind in three different scenarios: $(i)$ without DVA, (ii) with DVA, and (iii) with a hybrid damper, that is composed by a DVA and an LQR controlled actuator.

\subsection{Wind Turbine Numerical Model}

The wind turbine tower used in this work was similar to that modeled by $[15,16]$, having only changed parameters regarding the wall thickness of the tower. The model consists of spatial beam elements having six degrees of freedom per node, which allows obtaining both compression/tension, shear, bending moments, and torsion loads. The structure consists of 60 nodes, that are connected by 59 elements, being 20 elements for the tower, 9 to the nacelle, and 10 for each wing of the turbine. Additionally, consideration of the mass of the elements, through specific mass of materials, added to the global mass matrix, point masses were also added to nacelle nodes, due to the importance and representativeness to the total mass of the structure. For the simulation of cases with DVA, a new node was added to the structure, connected to the

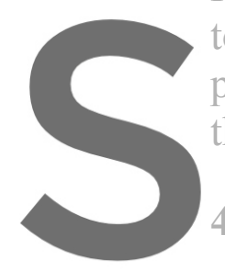
top of the tower, This no plane of the section cros the DVA goes oscillate

4.2 Generation of wind load action
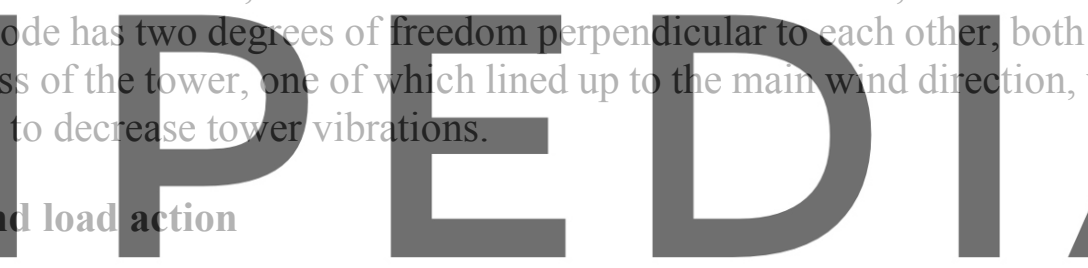

The action of the wind was simulated by modeling the velocity in two parts, the average

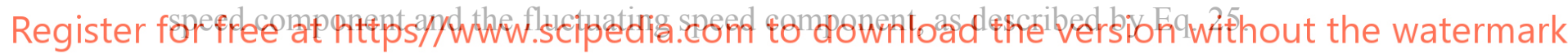

$$
u(y, z, t)=\bar{U}(z)+\tilde{u}(y, z, t)
$$

where $u(t)$ is he wind velocity at a defined time instant, $\bar{U}(z)$ it is average speed, modeled from the hypothesis of atmospheric boundary layer: $\bar{U}(z)=u_{r}\left(z / z_{r}\right)^{\alpha}$, where is the wind speed in a reference height $z_{r}$, being $\alpha$ a coefficient determined based on the soil roughness. The last portion of Eq.(25) refers to the random wind component and is the result of a statistical analysis of wind. The spectrum used in this work was proposed by Von Kármám ${ }^{[17]}$. It has been demonstrated ${ }^{[18]}$ that the spectrum of Von Kármán proved more credible in the representation of wind turbine farms, both in scale and in the shape of the spectrum for free-flow conditions.

The wind field was generated using an algorithm develop by ${ }^{[19]}$, which is based in a Monte Carlo simulation and correlation matrix decomposition. As it is a large structure, the fluctuating in wind speed are not the same for all points, it is necessary to correlate these space fluctuations speeds, which allows identifying the fluctuations at each point of space. Such a correlation can be described by the Eq. $26^{[17]}$.

$$
\operatorname{Coh}(d, f)=\exp \left[-\frac{f \sqrt{C_{z}^{2}\left(z_{1}-z_{2}\right)+C_{y}^{2}\left(y_{1}-y_{2}\right)}}{\bar{U}}\right]
$$


where Coh means the spatial correlation of velocities, $y_{1}, y_{2}, z_{1}$ and $z_{2}$ are the coordinates of two points on the face of structure hit by the wind, $f$ is the frequency in Hertz and $C_{z}$ and $C_{y}$ are empirical coefficients, being adopted for this work the values of $C_{z}=7 \mathrm{~m}$ and $C_{y}=10 \mathrm{~m}$, which produce correlated speed and load distributions that happens similar to wind turbine towers on open spaces where the investigated tower is installed.

The drag force on the structure was calculated using the Eq. 27, which results in a stepped force applied as localized forces on each DOF of the model.

$$
F_{n}=A_{n} C_{D}(R e) \rho[\bar{U}(z)+\tilde{u}(y 7, z, t)]^{2},
$$

where $A_{n}$ is the area of the two halves adjacent to the node in question, $C_{D}$ is the drag coefficient and $\rho$ is the specific mass of air. The resulting force on the turbine wings is calculated considering both the drag and the lift coefficients. This last coefficient induces torsion on the wind turbine axis since the blades are completely stopped.

\section{RESULTS}

Based on the described methodology, a code was developed in the software MATLAB. The routine was applied to the wind turbine model presented in section 3.1, varying the input parameters $[Q],[\boldsymbol{R}]$ and $\gamma$. The parameter $\gamma$ was taken as $1 \%$, being in the order of magnitude recommended in the related literature ${ }^{[13]}$.

This work sought to reduce the accelerations on the top of the tower, thus decreasing the

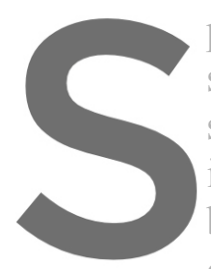
potential damage to the storm that may reach the stresses on the towe indicated, only 2 DVA below nacelle) and $t$ correspond to the first bending modes of the components present in the nacelle in
the place where the wind turbine is it
which contribute significantiy to the
were used for directions $x$ and $y$ positi
ned to the first two damped frequenc
bending modes of the tower, lateral respectively. The frequencies, to which the DVA have been tuned were the first and second

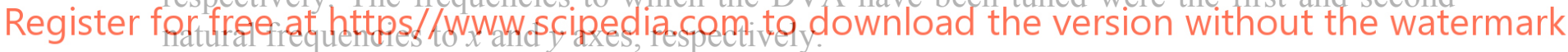

The wind excitation was generated according to the methodology described in section 3.2, considering an average wind speed of $25 \mathrm{~m} / \mathrm{s}$ at a reference height of $10 \mathrm{~m}$, which is quite severe for wind turbines, generating winds of $31 \mathrm{~m} / \mathrm{s}$ at the top height of the nacelle. A usual value for the cutting speed in most of power curves is $25 \mathrm{~m} / \mathrm{s}$ at the height of the nacelle, in the analyzed situation, the brakes are applied to the wind turbine wings, which is not in service. For fair comparisons, in all simulations, the same random wind profile was maintained so that the results could be comparable.

\subsection{Tower top accelerations}

Figure 4 shows the arrangement of the axes about the tower model. The accelerations on the $\mathrm{x}$ and $\mathrm{y}$ axes measured at the top of the tower are shown in Figure 5, where the representation black is used for the case without DVA (indicated by index ' $w$ '), in blue the case with passive DVA (indicated by index ' $d v a$ '), and in red the case with hybrid DVA (indicated with ' $h$ ' index). 


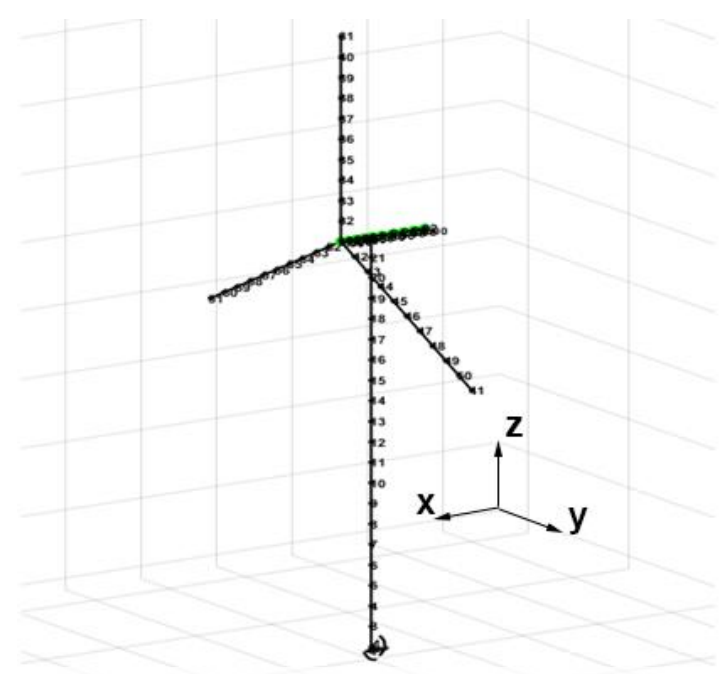

Figure 4: Tower model with axis orientation.
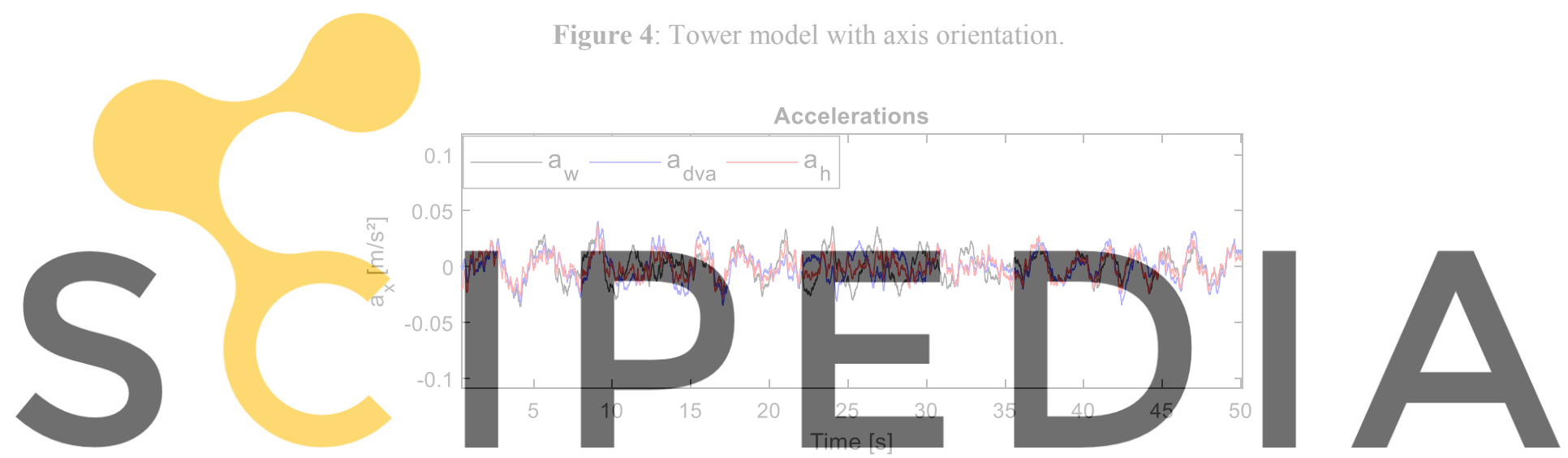

Accelerations

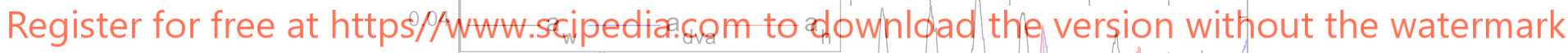

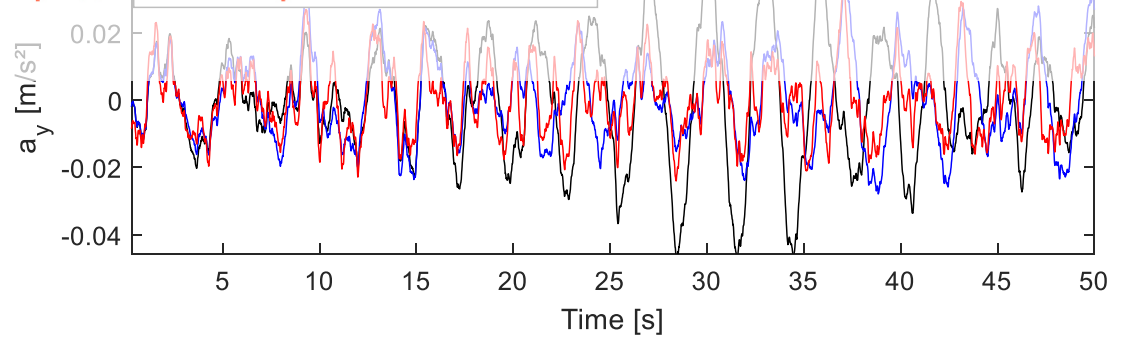

Figure 5: Acceleration measured at the top of the wind turbine tower.

It is seen that the acceleration spikes are much bigger in the case without DVA. It is still clear that the DVA is not as effective in one direction, this is due to the random nature of the wind excitation. The DVA is designed to match the first two natural frequencies (bending modes) of the structure, in which case it would achieve attenuations of $90 \%{ }^{[10]}$ in case of external excitations coupled with these natural frequencies. Analyzing Table 2, in the case of wind action, comparing the RMS values, the hybrid control has a significant role in reducing acceleration. 
Table 2: Tower top accelerations.

\begin{tabular}{ccccccc}
\cline { 2 - 6 } & \multicolumn{2}{c}{ Without control } & \multicolumn{2}{c}{ Passive control, DVA } & \multicolumn{2}{c}{ Hybrid control } \\
\cline { 2 - 7 } & $\begin{array}{c}\text { Absolute } \\
\text { maximum }\end{array}$ & RMS & $\begin{array}{c}\text { Absolute } \\
\text { maximum }\end{array}$ & RMS & $\begin{array}{c}\text { Absolute } \\
\text { maximum }\end{array}$ & RMS \\
\hline$x\left(\mathrm{~m} / \mathrm{s}^{2}\right)$ & $3.67 \times 10^{-2}$ & $1.30 \times 10^{-2}$ & $4.07 \times 10^{-2}$ & $1.28 \times 10^{-2}$ & $3.64 \times 10^{-2}$ & $1.05 \times 10^{-2}$ \\
\hline$y\left(\mathrm{~m} / \mathrm{s}^{2}\right)$ & $5.07 \times 10^{-2}$ & $1.84 \times 10^{-2}$ & $3.69 \times 10^{-2}$ & $1.27 \times 10^{-2}$ & $3.69 \times 10^{-2}$ & $1.07 \times 10^{-2}$ \\
\hline
\end{tabular}

Percentage of reduction in RMS acceleration

\begin{tabular}{lccc}
\cline { 2 - 4 } & $\begin{array}{c}\text { Without control } \rightarrow \\
\text { Passive control }\end{array}$ & $\begin{array}{c}\text { Passive control } \rightarrow \\
\text { Hybrid control }\end{array}$ & $\begin{array}{c}\text { Without control } \rightarrow \\
\text { Hybrid control }\end{array}$ \\
\cline { 2 - 4 } & $-1.73 \%$ & $-18.12 \%$ & $-19.54 \%$ \\
\hline$y\left(\mathrm{~m} / \mathrm{s}^{2}\right)$ & $-30.98 \%$ & $-15.86 \%$ & $-41.93 \%$ \\
\hline$y\left(\mathrm{~m} / \mathrm{s}^{2}\right)$ & & & \\
\hline
\end{tabular}

\subsection{Tower base reactions}

The most relevant reactions measured at the base of the tower, which are represented in Figure 6, are the shear reaction forces $R_{x}, R_{y}, R_{z}$, bending moments $M r_{x}$ and $M r_{y}$ and the torsional moment $\mathrm{Mr}_{z}$.
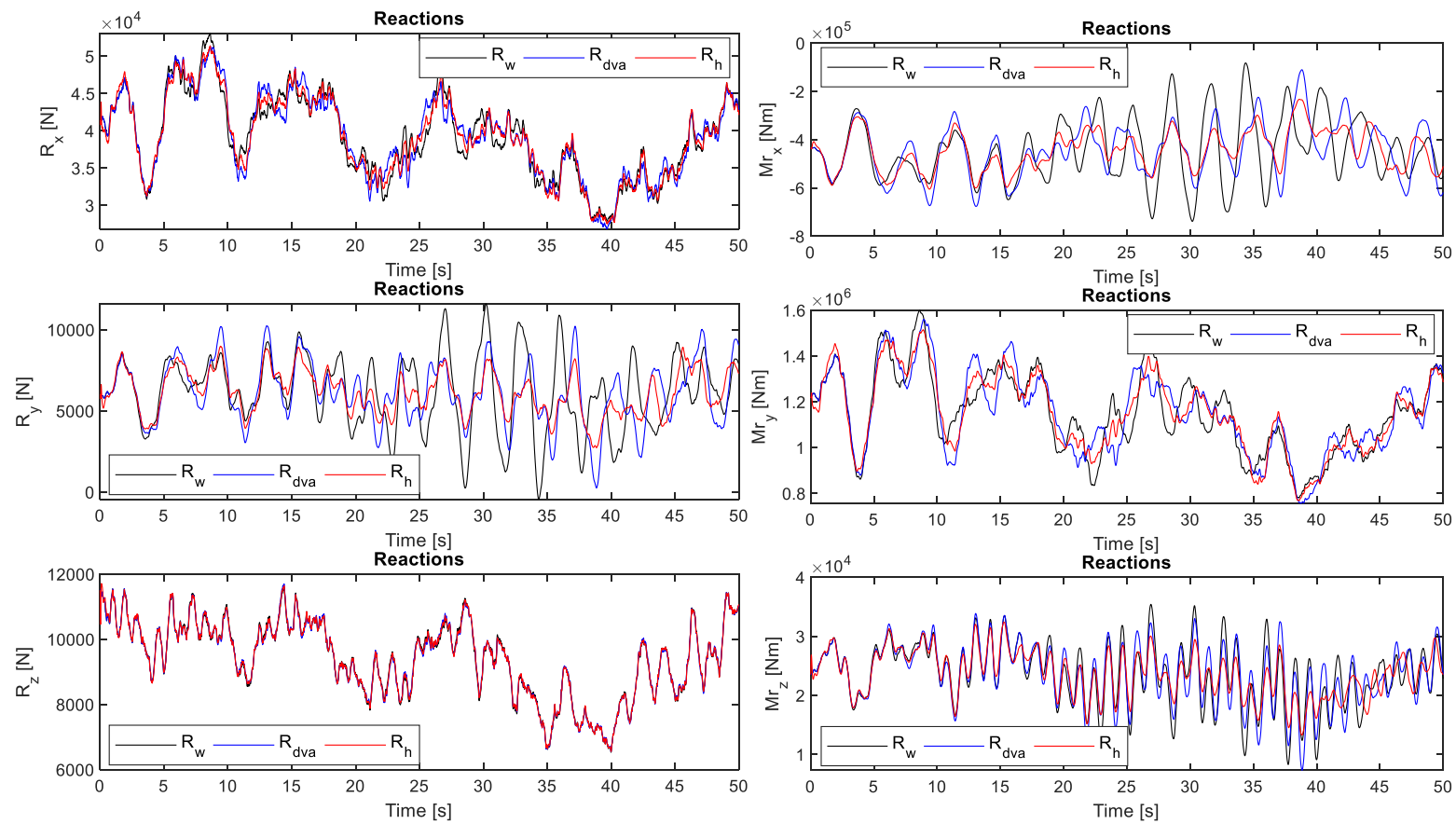

Figure 6: Reactions (Moments and forces) at the base of the wind turbine tower.

It can be seen that the reactions oscillate around the same average value for the three distinct cases, the bigger contribution of dampers in decreasing the amplitude of oscillation reactions, which is demonstrated in Table 3. 
Table 3: Reactions measured at the base of the wind turbine tower.

\begin{tabular}{|c|c|c|c|c|c|c|}
\hline & \multicolumn{2}{|c|}{ Without control } & \multicolumn{2}{|c|}{ Passive control, DVA } & \multicolumn{2}{|c|}{ Hybrid control } \\
\hline & RMS & Std. dev. & RMS & Std. dev. & RMS & Std. dev. \\
\hline $\mathrm{Fz}(\mathrm{N})$ & $6.54 \times 10^{3}$ & $2.27 \times 10^{3}$ & $6.41 \times 10^{3}$ & $1.87 \times 10^{3}$ & $6.29 \times 10^{3}$ & $1.35 \times 10^{3}$ \\
\hline $\mathrm{Mx}(\mathrm{Nm})$ & $2.42 \times 10^{4}$ & $5.10 \times 10^{3}$ & $2.42 \times 10^{4}$ & $4.90 \times 10^{3}$ & $2.40 \times 10^{4}$ & $3.90 \times 10^{3}$ \\
\hline \multirow[t]{3}{*}{ My $(\mathrm{Nm})$} & $4.62 \times 10^{5}$ & $1.31 \times 10^{5}$ & $4.56 \times 10^{5}$ & $1.09 \times 10^{5}$ & $4.51 \times 10^{5}$ & $8.16 \times 10^{4}$ \\
\hline & \multicolumn{6}{|c|}{ Percentage of reduction in RMS. } \\
\hline & \multicolumn{2}{|c|}{$\begin{array}{l}\text { Without control } \rightarrow \\
\text { Passive control }\end{array}$} & \multicolumn{2}{|c|}{$\begin{array}{c}\text { Passive Control } \rightarrow \\
\text { Hybrid control }\end{array}$} & \multicolumn{2}{|c|}{$\begin{array}{c}\text { Without control } \rightarrow \\
\text { Hybrid control }\end{array}$} \\
\hline $\mathrm{Fz}(\mathrm{N})$ & \multicolumn{2}{|c|}{$-17.59 \%$} & \multicolumn{2}{|c|}{$-27.62 \%$} & \multicolumn{2}{|c|}{$-40.35 \%$} \\
\hline $\mathrm{Mx}(\mathrm{Nm})$ & \multicolumn{2}{|c|}{$-4.16 \%$} & \multicolumn{2}{|c|}{$-20.47 \%$} & \multicolumn{2}{|c|}{$-23.78 \%$} \\
\hline My (Nm) & \multicolumn{2}{|c|}{$-16.93 \%$} & \multicolumn{2}{|c|}{$-25.21 \%$} & \multicolumn{2}{|c|}{$-37.87 \%$} \\
\hline
\end{tabular}

\subsection{Loads at element of the base of the tower}

The most relevant efforts measured at the base of the tower are represented in Figure 7 , which are the axial forces $\mathrm{Fz}$ and bending moments $\mathrm{Mx}$ and My. For the $\mathrm{Z}$ force, and $\mathrm{X}$ and $\mathrm{Y}$ moments can be said that in the same way as the reactions, the r.m.s value remained stable, but the variation in relation to the average had decreased considerably. The main values are listed in Table 4.

Table 4: Moment reactions at the base of Wind turbine tower.

\begin{tabular}{|c|c|c|c|c|c|c|}
\hline & \multicolumn{2}{|c|}{ Without control } & \multicolumn{2}{|c|}{ Passive control, DVA } & \multicolumn{2}{|c|}{ Hybrid control } \\
\hline & RMS & std. dev. & RMS & std. dev. & RMS & std. dev. \\
\hline$M_{\mathrm{x}}(\mathrm{Nm})$ & $4.62 \times 10^{5}$ & $1.31 \times 10^{5}$ & $4.56 \times 10^{5}$ & $1.09 \times 10^{5}$ & $4.51 \times 10^{5}$ & $8.16 \times 10^{4}$ \\
\hline$M_{\mathrm{y}}(\mathrm{Nm})$ & $1.16 \times 10^{6}$ & $1.78 \times 10^{5}$ & $1.16 \times 10^{6}$ & $1.78 \times 10^{5}$ & $1.16 \times 10^{6}$ & $1.70 \times 10^{5}$ \\
\hline \multirow[t]{3}{*}{$M_{\mathrm{z}}(\mathrm{Nm})$} & $2.42 \times 10^{4}$ & $5.10 \times 10^{3}$ & $2.42 \times 10^{4}$ & $4.90 \times 10^{3}$ & $2.40 \times 10^{4}$ & $3.90 \times 10^{3}$ \\
\hline & \multicolumn{6}{|c|}{ Percentage of reduction in std. dev. } \\
\hline & \multicolumn{2}{|c|}{$\begin{array}{l}\text { Without control } \rightarrow \\
\text { Passive control } \\
\end{array}$} & \multicolumn{2}{|c|}{$\begin{array}{c}\text { Passive control } \rightarrow \\
\text { Hybrid control } \\
\end{array}$} & \multicolumn{2}{|c|}{$\begin{array}{l}\text { Without control } \rightarrow \\
\text { Hybrid control }\end{array}$} \\
\hline$M_{x}(\mathrm{Nm})$ & \multicolumn{2}{|c|}{$-16.93 \%$} & \multicolumn{2}{|c|}{$-25.21 \%$} & \multicolumn{2}{|c|}{$-37.87 \%$} \\
\hline$M_{y}(\mathrm{Nm})$ & \multicolumn{2}{|c|}{$-0.06 \%$} & \multicolumn{2}{|c|}{$-4.55 \%$} & \multicolumn{2}{|c|}{$-4.61 \%$} \\
\hline$M_{z}(\mathrm{Nm})$ & \multicolumn{2}{|c|}{$-4.16 \%$} & \multicolumn{2}{|c|}{$-20.47 \%$} & \multicolumn{2}{|c|}{$-23.78 \%$} \\
\hline
\end{tabular}



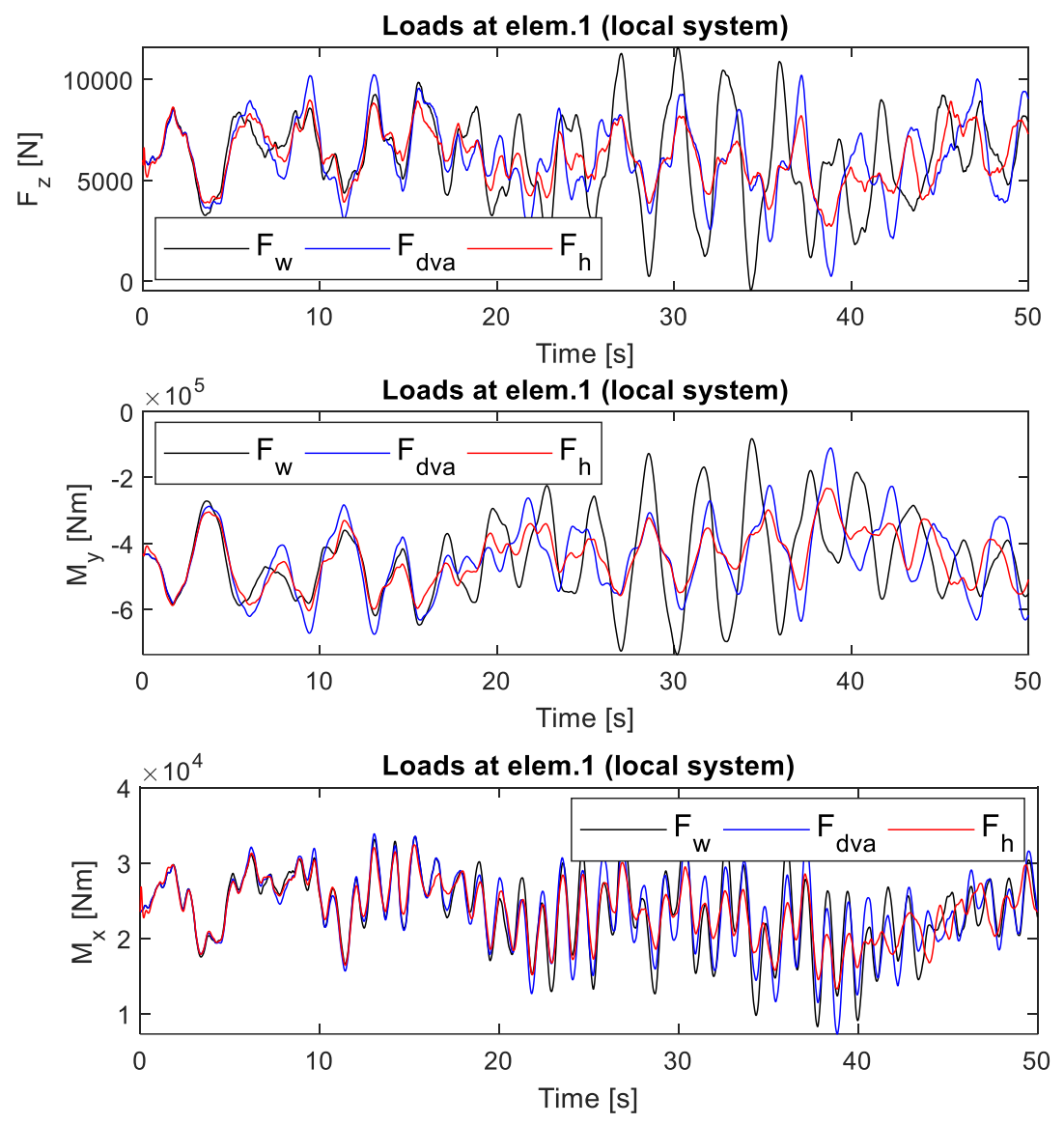

Figure 7: Loads at the base of the wind turbine tower.

As it happens at the base of the Wind Turbine Tower, the loads oscillate around the same average values, the bigger contribution of dampers to the reduction of the oscillation amplitude of the loads, which are demonstrated in Table 5.

Table 5:-Loads at the base of the wind turbine tower.

\begin{tabular}{ccccccc} 
& \multicolumn{2}{c}{ Without control } & \multicolumn{2}{c}{ Passive control, DVA } & \multicolumn{2}{c}{ Hybrid control } \\
\cline { 2 - 7 } & RMS & std.dev. & RMS & std.dev. & RMS & std.dev. \\
\hline Fz $(\mathrm{N})$ & $6.54 \times 10^{3}$ & $2.27 \times 10^{3}$ & $6.41 \times 10^{3}$ & $1.87 \times 10^{3}$ & $6.29 \times 10^{3}$ & $1.35 \times 10^{3}$ \\
\hline $\mathrm{Mx}(\mathrm{Nm})$ & $2.42 \times 10^{4}$ & $5.10 \times 10^{3}$ & $2.42 \times 10^{4}$ & $4.90 \times 10^{3}$ & $2.40 \times 10^{4}$ & $3.90 \times 10^{3}$ \\
\hline $\mathrm{My}(\mathrm{Nm})$ & $4.62 \times 10^{5}$ & $1.31 \times 10^{5}$ & $4.56 \times 10^{5}$ & $1.09 \times 10^{5}$ & $4.51 \times 10^{5}$ & $8.16 \times 10^{4}$ \\
\hline
\end{tabular}

Percentage of reduction in std. dev.

\begin{tabular}{cccc}
\cline { 2 - 4 } & $\begin{array}{c}\text { Without control } \rightarrow \\
\text { Passive control }\end{array}$ & $\begin{array}{c}\text { Passive control } \rightarrow \\
\text { Hybrid control }\end{array}$ & $\begin{array}{c}\text { Without control } \rightarrow \\
\text { Hybrid control }\end{array}$ \\
\hline $\mathrm{Fz}(\mathrm{N})$ & $-17.59 \%$ & $-27.62 \%$ & $-40.35 \%$ \\
\hline $\mathrm{Mx}(\mathrm{Nm})$ & $-4.16 \%$ & $-20.47 \%$ & $-23.78 \%$ \\
\hline $\mathrm{My}(\mathrm{Nm})$ & $-16.93 \%$ & $-25.21 \%$ & $-37.87 \%$ \\
\hline
\end{tabular}




\subsection{Control forces}

The control forces aim to move the DVA mass by an actuator. The forces performed by the dampers actuators positioned in $\mathrm{x}$ and $\mathrm{y}$ directions are represented in Figure 8.
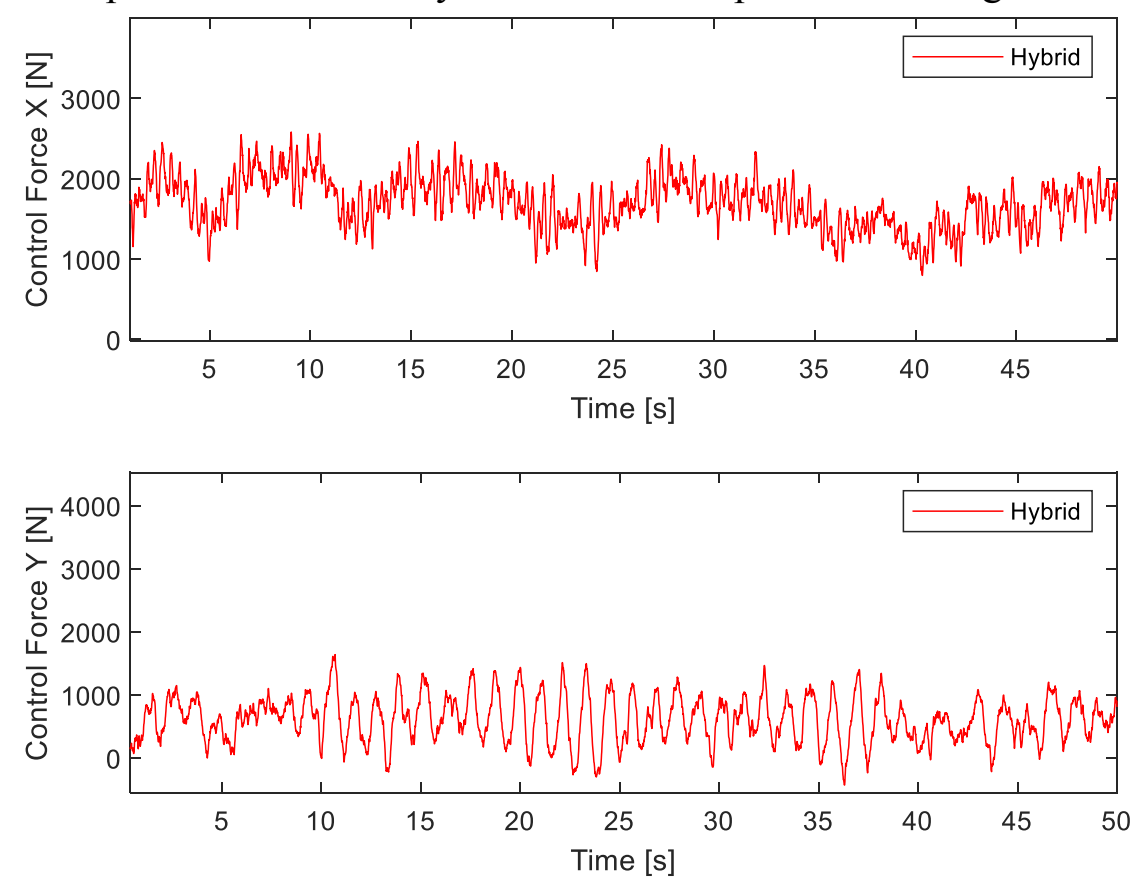

Figure 8: Control forces of the hybrid DVA.

The maximum observed forces for this case are $2581 \mathrm{~N}$ for the $\mathrm{x}$-axis and $1637 \mathrm{~N}$ for the $\mathrm{y}$ axis. This is in accordance with the maximum allowed forces applied by commercial pneumatic cylinders, e.g. Heavy Duty line - 3400 and 3520 series $^{[20]}$.

\subsection{DVA Displacement}

The mass displacement of the DVA was one of the limiting factors for the damping of the structure, as there is limited space inside the tower. The mass of DVA is $1 \%$ of the structure, which is $7290 \mathrm{~kg}$. Considering the mass would be made of lead, with a mass density of 11340 $\mathrm{kg} / \mathrm{m}^{3}$, it is necessary an $87 \mathrm{~cm}$ side spam. As the interior of the tower has a diameter of $1.14 \mathrm{~m}$, then $13.5 \mathrm{~cm}$ would remain for the oscillation on each side. Figure 9 shows the displacement of the DVA mass over time for cases with passive and hybrid control, in both directions. 

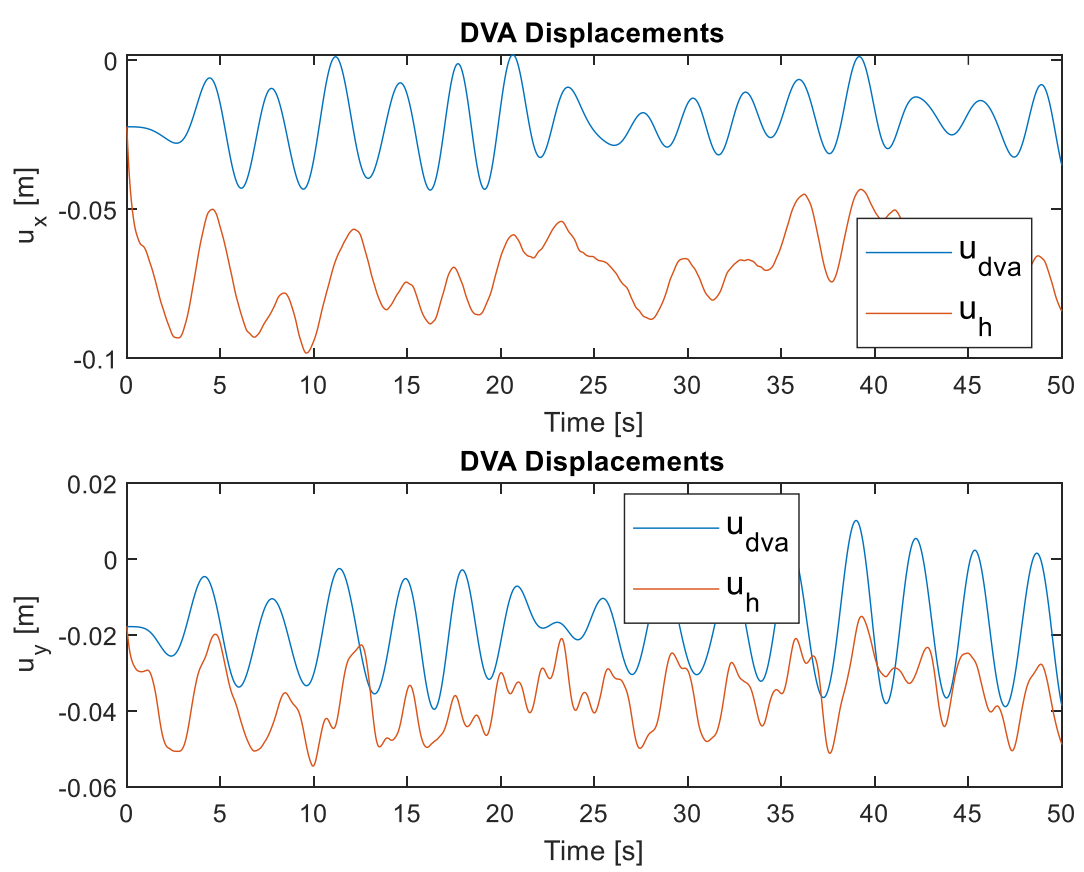

Figure 9: DVA mass displacement for cases with passive and hybrid control.

Thus, can be seen that the maximum oscillation is $9.8 \mathrm{~cm}$ in the case of the hybrid control and $4.3 \mathrm{~cm}$ in the case of passive control, both are within the allowed range of oscillation. Possibly due to the presence of other components, such as string, damper, and actuator, the mass geometry may change, which is not in the scope of this work, but such changes would not significantly interfere in the mass size, which may still be contained by the tower.

\section{CONCLUSION}

The present work developed a comparative study in the use of tuned mass dampers in wind turbine towers to mitigate the vibration due to wind action. The ground reaction forces at the base of the structure benefits from the effect in reducing accelerations at the nacelle. Three different scenarios were considered: without damping, with passive damping, and with hybrid active control, containing the mass of the DVA and control forces generated by an actuator (active + passive).

The design of the tuned mass damper follows the traditional way presented by Denhartog (1985), which is ideally applicable to structures without structural damping, but demonstrates satisfactory results for structures with low damping. The introduced hybrid control was designed using the linear quadratic controller theory, and the theory of optimal control.

After analysis performed by this work, it is seen that passive control presents a certain improvement in acceleration parameters, reactions, and loads, but in some cases, it is not efficient due to the random nature of wind excitation, given that DVA is designed for some specific frequency. Especially concerning this fact, the hybrid control presented satisfactory results, since it responds to the actual sensed dynamics of the structure and doesn't hold to just one frequency. 
It is important to note that the accelerations presented reductions in their average value, and this fact did not occur for tower loads and base reactions. They just had their amplitude reduced. This contributes to the reduction in the structural fatigue caused by wind loads.

For future works, it is suggested the study of different wind spectra, the analysis of wave effects, for offshore wind farms, and earthquakes. It is also suggested the use different DVA strategies, such as tuned liquid dampers, fluid dampers, or pendulum dampers.

\section{References}

[1] EBC. Brazilian Communication Company. Brazil is the eighth country in the world in wind energy production. Acessed 15th February. (2019). <http://agenciabrasil.ebc.com.br/ economia/noticia/2018-02/brasil-e-o-oitavo-pais-do-mundo-em-producao-de-energia-eolica $>$

[2] Rahman, M. Performance enhancement of wind turbine systems with vibration control: A review. Renewable and Sustainable Energy Reviews, (2015) 51:43-54. https://doi.org/10.1016/j.rser.2015.05.078.

[3] Denhartog, J. P. Mechanical vibrations. Courier Corporation, (1985).

[4] Sakai, F., Takaeda, S., Tamaki, T. Tuned liquid column damper: new type device for suppression of building vibration. Proceedings of International Conference on High-rise Buildings, Nanjing, China, (1989), p.926-931.

[5] Ghaemmachami, A., Kianoush, R., Yuan, X.-X. Numerical Modeling of Dynamic Behavior of Annular Tuned Liquid Dampers for Applications in Wind Towers. Computer-aided Civil and Infrastructure Engineering, (2012) 28(1):38-51. https://doi.org/10.1111/j.1467$\underline{8667.2012 .00772 . \mathrm{x}}$

[6] Alkmin, M. H. Vibration control in wind turbine using passive tuned liquid column absorber. 81p. Mechanical Engineering Department, Federal University of Brasília, Brazil, (2015).

[7] Caterino, N. Semi-active control of a wind turbine via magnetorheological dampers. Journal of Sound and Vibration, (2015) 345:1-17. https://doi.org/10.1016/j.jsv.2015.01.022

[8] Basu, B. Vibration and Power Control of Wind Turbines. Aalborg, Denmark, 69 p., (2014).

[9] Staino, A., Basu, B. Emerging trends in vibration control of wind turbines: A focus on a dual control strategy. Philosophical Transactions of The Royal Society: A Mathematical Physical and Engineering Sciences (2015) 373(2035). https://doi.org/10.1098/rsta.2014.0069.

[10] Lima, D. M., López-Yánez, P. A., Alves, M. A. P. Vibration control device for steel tubular towers of Horizontal Axis Wind Turbines. Latin American Journal of Solids and Structures, (2019) 16(6). https://doi.org/10.1590/1679-78255436

[11] Rao, S. S. Mechanical Vibrations, $6^{\text {th }}$. Edition, Pearson Ed, 1112 p., (2011).

[12] Clough, R. W., Penzien, J. Dynamics of Structures. Publisher: McGraw-Hill College; $2^{\text {nd }}$. Ed., 768p. (1993).

[13] Dazio, A. Fundamentals of Structural Dynamics. Nablus: An-Najah National University, 435 p. (2013).

[14] Kwon, Y., Bang, H. The Finite Element Method Using MATLAB. Boca Raton, Florida: CRC Press, 544 p. (1997).

[15] Furlanetto, A., Gomes, H. M., Almeida, F. S. Design optimization of tapered steel wind turbine towers by QPSO algorithm. International Journal of Steel Structures, (2020) 1:1-12. http://dx.doi.org/10.1007/s13296-020-00389-3 
[16] Foschiera, L. C. Dynamic analysis of wind generator towers under random wind loading (in Portuguese). (2018). 15p. Monograph. Mechanical Engineering Department, Federal University of Rio Grande do Sul, Brazil, (2018).

[17] Davenport, A. G. The spectrum of horizontal gustiness near the ground in high winds. Q.J.R. Meteorol. Soc. (1961) 87:194-211. https://doi.org/10.1002/qj.49708737208

[18] Mofiadakis, E. E., Glinou, G. L., Koulouvari, M. J. The suitability of the von Karman spectrum for the structure of turbulence in a complex terrain wind farm. J. of Wind Engrg. and Ind. Aerod., (1996) 62:237-257. https://doi.org/10.1016/S0167-6105(96)00059-1

[19] J. Wang, Cheynet, E., Snaebjöornsson, J. P., Jakobsen, J. B. Coupled aerodynamic and hydrodynamic response of a long span bridge suspended from floating towers. J. of Wind Energy and Ind. Aerod. (2018) 177:19-31.

[20] Parker Automation. Pneumatic Line: Catalog 1001-6 BR (2007). Accessed 30 november, 2019. <https://www.parker.com/parkerimages/br/download/automation/pdf/1001_6_BR.pdf >. 